https://doi.org/10.15407/ujpe64.4.300

V.YA. DEGODA, M. ALIZADEH

Taras Shevchenko National University of Kyiv

(64, Volodymyrs'ka Str., Kyiv 01601, Ukraine)

\title{
PARAMETERS OF CHARGE CARRIER TRAPS IN ZnSe
}

\begin{abstract}
Taking zinc selenide ( $\mathrm{ZnSe}$ ) crystals as an example, a procedure of determination of the main parameters of traps is proposed. At first, the conductivity type (electron or hole one) in a crystal of phosphor at its excitation is determined with the help of photoelectric studies or studies of the thermionic emission or thermal or photo-thermal emf. Then the energy of the thermal electron delocalization is determined, e.g., by using the method of thermally stimulated luminescence with sequential fractional heating. As a result, the frequency factors of corresponding traps are found as well. Knowing the effective electron mass, it is easy to calculate the effective density of electron states in the conduction band. Finally, the cross sections of the free-electron localization and their temperature dependences can be determined for all traps from a simple equation.
\end{abstract}

Ke ywords: charge carrier traps, recombination centers, localization centers, delocalization centers, zinc selenide.

\section{Introduction}

Defects of a crystal structure that are responsible for the appearance of local levels in the forbidden gap of semiconductors and insulators govern the kinetics of luminescence and conductivity in those materials. The corresponding kinetic researches, which were carried out during 70 years, made it possible to reveal all physical processes that take place in the materials at their excitation and develop the kinetic theories of luminescence $[1,2]$ and conductivity $[3,4]$.

Point defects are classified into recombination centers (radiative and non-radiative) and traps for free charge carriers. Such a classification is rather relative, because the luminescence centers also play the role of traps for the first free charge carrier and create recharged recombination centers at the initial stage. Only afterward, the localization of a charge carrier with the opposite sign at this center leads to the recombination of charges and the emission of light quanta. The recombination can also take place

(c) V.YA. DEGODA, M. ALIZADEH, 2019 at recharged traps. But, in many cases, it is the non-radiative recombination even at low temperatures. It should be noted that both traps and luminescence centers are recombination centers for free excitons. The radiative recombination centers (luminescence centers) determine, first of all, luminescence spectra; whereas the traps determine the light sum accumulated at the excitation, as well as the kinetics of luminescence and conductivity. Therefore, one of the main tasks is to find the parameters of traps in the materials.

The first methods for determining the kinetic parameters of local centers appeared together with the kinetic methods of experimental studies. They are mainly used to find the parameters of the recombination centers in wide-band-gap semiconductors [2-8]. Recently, the measurements of the Schottky barrier capacitance were used to determine the trap parameters in narrow-band-gap semiconductors [9]. Thus, there are experimental methods for determining the parameters of luminescence centers, but there are no reliable and unambiguous methods for

ISSN 2071-0194. Ukr. J. Phys. 2019. Vol. 64, No. 4 
determining the parameters of traps (except for their depth). For instance, traps with energies of 0.56 and $0.44 \mathrm{eV}$ are observed in GaAs. The difference between the indicated values amounts to $27 \%$. At the same time, the corresponding localization cross-sections differ from each other by an order of magnitude, with the value for the shallower trap being smaller.

The well-known ZnSe crystals are a good model material for relevant studies. They demonstrate the intense luminescence and conductivity, when being excited with X-ray and UV quanta, which allows the complex kinetic researches and the determination of trap parameters to be performed simultaneously. In the general case, the traps for free charge carriers in crystalline phosphors are characterized by the following parameter:

1. the trap depth $E_{i}$, which describes the depth of a local level in the forbidden gap;

2 . the frequency factor $\omega_{0 i}$; together with the temperature $T$, this parameter determines the probability of the thermal delocalization of a charge carrier from this trap, $\omega_{i}=\omega_{0 i} \exp \left(-E_{i} / k T\right)$;

3 . the localization cross-section $\sigma_{i}^{ \pm}$; the subscript indicates the type of a localization center, and the superscript gives the sign of the free charge carrier.

In this work, the attempt was made to relate the main parameters of traps in specially undoped ZnSe crystals with one another and to determine their temperature dependences.

\section{Trap Depth $E_{i}$}

The presence of traps in a material can be detected from the curves of thermally stimulated luminescence (TSL) and conductivity (TSC), which are registered, when the specimen is heated after its excitation. Almost all crystalline phosphors demonstrate dozens of TSL peaks, which testifies to a wide spectrum of traps in every specimen. As a rule, different specimens of the same material reveal different ratios between the peak intensities, both in the TSL and TSC curves. This fact means that minor deviations in the crystal growing technology may bring to significant changes in the concentrations of various traps.

For the reliable determination of the whole trap spectrum, several excitation temperatures have to be used, especially in the case of wide-band-gap materials. The most convenient way is to use the liquid helium temperature $(4.2 \mathrm{~K})$, liquid nitrogen temper- ature $(77 \mathrm{~K})$, and room temperature $(295 \mathrm{~K})$. For the determination of the thermal depth of a trap, the most reliable method is TSL with the fractional heating [10], because it is based on the fundamental relationship: the initial intensity of a TSL peak is proportional to the probability of the charge carrier delocalization from a trap.

The detailed researches of the trap energy spectrum showed that, in various crystals - e.g., $\mathrm{Ba}_{2} \mathrm{NaNb}_{5} \mathrm{O}_{15}$ [11], $\mathrm{CdWO}_{4}$ [12], $\mathrm{ZnWO}_{4}$ [13], $\mathrm{Al}_{2} \mathrm{O}_{3}$ [14], $\mathrm{CsCdCl}_{3}$ [15], $\mathrm{Y}_{3} \mathrm{Al}_{5} \mathrm{O}_{12}$ [16], $\mathrm{NaCl}$ [17], $\mathrm{LiF}$ [18], $\mathrm{KCl}$ and $\mathrm{NaI}$ [19], ZnS:Cu [20], AlN:O [21], $\mathrm{PbSO}_{4}$ [22], CaS [23] and ZnSe [24] - the energy positions of local trap levels are equidistant and can be described by the harmonic oscillator formula

$E_{i}=\hbar \omega\left(i+\frac{1}{2}\right)$

where: $i=0,1,2,3, \ldots$ is the ordinal number of the trap type, and the equidistance constant $\hbar \omega$ is identical to the energy of a totally symmetric vibration of the crystalline lattice. For ZnSe crystals, the parameter $\hbar \omega=0.02567 \mathrm{eV}\left(206 \mathrm{~cm}^{-1}\right)$ was obtained. Such a behavior of the trap energy spectrum can be explained in the framework of the polaron trap model [10]. Accordingly, we obtain that the parameter $i$ determines the number of vibrational levels in the trap.

On the other hand, it has long been known that if the heating rate $\beta$ is constant, a linear relation takes place between the trap depth and the corresponding temperature position $T_{i}$ of the TSL peak [25-27],

$E_{i}=A \times k T_{i}$

The dimensionless constant $A$ lies within an interval from 20 to 25 for all known crystalline phosphors. Thus, the method of fractional luminescence [10] can be used to experimentally determine the trap depths for the most intense TSL peaks and verify the validity of relations (1) and (2). As a result, we can determine $E_{i^{-}}$and $T_{i}$-values for all traps in the given crystalline phosphor. The values of trap depths for ZnSe crystals are quoted in Table. The fourth column of the table contains the experimentally obtained depth values for the traps corresponding to the most intense TSL peaks. The symbol "+" marks traps that are observed in the TSL curves, so that their $T_{i}$ can be evaluated, but their intensity is too low for the value of the parameter $E_{i}$ to be determined. 


\section{Frequency Factor of the Trap $\omega_{0 i}$}

Knowing the thermal depth of the trap, $E_{i}$, and the temperature position of its TSL peak, $T_{i}$, we can determine the corresponding frequency factor $\omega_{0 i}$ $[2,10,25,28]$ (this procedure can be done for every

Main parameters

of electron traps in $\mathrm{ZnSe}$ crystals

\begin{tabular}{|c|c|c|c|c|c|}
\hline$i$ & $\begin{array}{c}T_{m}, \\
\mathrm{~K}\end{array}$ & $\begin{array}{c}E_{i} \text { (theor) } \\
\mathrm{eV}\end{array}$ & $\begin{array}{c}E_{i}(\exp ) \\
\mathrm{eV}\end{array}$ & $\begin{array}{l}\omega_{0 i} \\
\mathrm{~s}^{-1}\end{array}$ & $\begin{array}{c}\sigma_{i}(8 \mathrm{~K}) \\
\mathrm{cm}^{-2}\end{array}$ \\
\hline 1 & 20.4 & 0.0385 & & $1.0 \mathrm{E}+09$ & $2.50 \mathrm{E}-16$ \\
\hline 2 & 34.0 & 0.0642 & & $6.3 \mathrm{E}+08$ & $1.50 \mathrm{E}-16$ \\
\hline 3 & 47.6 & 0.0898 & 0.09 & $4.5 \mathrm{E}+08$ & $1.10 \mathrm{E}-16$ \\
\hline 4 & 61.2 & 0.1155 & + & $3.5 \mathrm{E}+08$ & $8.40 \mathrm{E}-17$ \\
\hline 5 & 74.8 & 0.1412 & & $2.8 \mathrm{E}+08$ & $6.90 \mathrm{E}-17$ \\
\hline 6 & 88.4 & 0.1669 & & $2.4 \mathrm{E}+08$ & $5.80 \mathrm{E}-17$ \\
\hline 7 & 102.0 & 0.1925 & & $2.1 \mathrm{E}+08$ & $5.00 \mathrm{E}-17$ \\
\hline 8 & 115.6 & 0.2182 & & $1.8 \mathrm{E}+08$ & $4.50 \mathrm{E}-17$ \\
\hline 9 & 129.2 & 0.2439 & 0.24 & $1.6 \mathrm{E}+08$ & $4.00 \mathrm{E}-17$ \\
\hline 10 & 142.8 & 0.2695 & 0.27 & $1.5 \mathrm{E}+08$ & $3.60 \mathrm{E}-17$ \\
\hline 11 & 156.4 & 0.2952 & & $1.4 \mathrm{E}+08$ & $3.30 \mathrm{E}-17$ \\
\hline 12 & 170.0 & 0.3209 & 0.32 & $1.3 \mathrm{E}+08$ & $3.00 \mathrm{E}-17$ \\
\hline 13 & 183.6 & 0.3465 & 0.35 & $1.2 \mathrm{E}+08$ & $2.80 \mathrm{E}-17$ \\
\hline 14 & 197.2 & 0.3722 & + & $1.1 \mathrm{E}+08$ & $2.60 \mathrm{E}-17$ \\
\hline 15 & 210.8 & 0.3979 & & $1.0 \mathrm{E}+08$ & $2.40 \mathrm{E}-17$ \\
\hline 16 & 224.4 & 0.4236 & + & $9.5 \mathrm{E}+07$ & $2.30 \mathrm{E}-17$ \\
\hline 17 & 238.0 & 0.4492 & & $9.0 \mathrm{E}+07$ & $2.20 \mathrm{E}-17$ \\
\hline 18 & 251.6 & 0.4749 & 0.47 & $8.5 \mathrm{E}+07$ & $2.00 \mathrm{E}-17$ \\
\hline 19 & 265.2 & 0.5006 & + & $8.0 \mathrm{E}+07$ & $1.90 \mathrm{E}-17$ \\
\hline 20 & 278.8 & 0.5262 & & $7.6 \mathrm{E}+07$ & $1.80 \mathrm{E}-17$ \\
\hline 21 & 292.4 & 0.5519 & + & $7.3 \mathrm{E}+07$ & $1.80 \mathrm{E}-17$ \\
\hline 22 & 306.0 & 0.5776 & & $7.0 \mathrm{E}+07$ & $1.70 \mathrm{E}-17$ \\
\hline 23 & 319.6 & 0.6032 & 0.60 & $6.7 \mathrm{E}+07$ & $1.60 \mathrm{E}-17$ \\
\hline 24 & 333.2 & 0.6289 & & $6.4 \mathrm{E}+07$ & $1.50 \mathrm{E}-17$ \\
\hline 25 & 346.8 & 0.6546 & + & $6.1 \mathrm{E}+07$ & $1.50 \mathrm{E}-17$ \\
\hline 26 & 360.4 & 0.6803 & & $5.9 \mathrm{E}+07$ & $1.40 \mathrm{E}-17$ \\
\hline 27 & 374.0 & 0.7059 & & $5.7 \mathrm{E}+07$ & $1.40 \mathrm{E}-17$ \\
\hline 28 & 387.6 & 0.7316 & & $5.5 \mathrm{E}+07$ & $1.30 \mathrm{E}-17$ \\
\hline 29 & 401.2 & 0.7573 & & $5.3 \mathrm{E}+07$ & $1.30 \mathrm{E}-17$ \\
\hline 30 & 414.8 & 0.7829 & & $5.1 \mathrm{E}+07$ & $1.20 \mathrm{E}-17$ \\
\hline 31 & 428.4 & 0.8086 & & $5.0 \mathrm{E}+07$ & $1.20 \mathrm{E}-17$ \\
\hline 32 & 442.0 & 0.8343 & & $4.8 \mathrm{E}+07$ & $1.20 \mathrm{E}-17$ \\
\hline 33 & 455.6 & 0.8599 & & $4.7 \mathrm{E}+07$ & $1.10 \mathrm{E}-17$ \\
\hline 34 & 469.2 & 0.8856 & & $4.5 \mathrm{E}+07$ & $1.10 \mathrm{E}-17$ \\
\hline 35 & 482.8 & 0.9113 & & $4.4 \mathrm{E}+07$ & $1.10 \mathrm{E}-17$ \\
\hline 36 & 496.4 & 0.9370 & & $4.3 \mathrm{E}+07$ & $1.00 \mathrm{E}-17$ \\
\hline 37 & 510.0 & 0.9626 & & $4.2 \mathrm{E}+07$ & $1.00 \mathrm{E}-17$ \\
\hline 38 & 523.6 & 0.9883 & & $4.1 \mathrm{E}+07$ & $9.80 \mathrm{E}-18$ \\
\hline 39 & 537.2 & 1.0140 & & $4.0 \mathrm{E}+07$ & $9.60 \mathrm{E}-18$ \\
\hline 40 & 550.8 & 1.0396 & & $3.9 \mathrm{E}+07$ & $9.30 \mathrm{E}-18$ \\
\hline
\end{tabular}

trap):

$w_{0 i}=\frac{E_{i}}{k T_{i}}=\frac{A \beta}{T_{i}} \exp (A)=\frac{A^{2} k \beta}{E_{i}} \exp (A)$.

This relation shows that the frequency factor is inversely proportional to the trap depth. As a result, we can calculate the frequency factors for all possible traps in the given crystalline phosphor. In such a way, we can obtain parameters of the traps that are observed in TSL, even without knowing the origin of the traps themselves and which free charge carriers are localized at them.

For example, let us assume that the traps that are observed in the TSL and TSC curves are electron ones, because this is true for many other wideband-gap semiconductors $[4,5]$. Since the energy of the traps is described by the harmonic oscillator formula (1), the localization and delocalization processes can be considered in the framework of the polaron model [10]. For an ensemble of identical filled traps, the statistical distribution over vibrational levels have to be described by the Boltzmann formula

$$
\begin{aligned}
& \frac{N_{m}}{N_{k}}=\frac{g_{m}}{g_{k}} \exp \left(\frac{E_{k}-E_{m}}{k T}\right)=\exp \left(\frac{E_{m}-E_{k}}{k T}\right)= \\
& =\exp \left(\frac{\hbar \omega_{c}(k-m)}{k T}\right),
\end{aligned}
$$

where $0 \leqslant(m, k) \leqslant i-1$ are the numbers of vibrational levels of the filled trap. For a harmonic oscillator, the statistical weights $g_{m}$ and $g_{k}$ of vibrational levels are identical. At $T \neq 0$, all vibrational levels, including those above $E_{i}$, must be occupied with probabilities different from zero.

Let us determine the fraction of transitions with the trap ionization (the electron delocalization into the conduction band) owing to the population of vibrational levels with energies larger than $E_{i}$. From the normalization condition for the Boltzmann distribution, we obtain the quasiequilibrium concentration of filled traps, $n_{i}$, and, accordingly, the distribution of concentrations over the vibrational levels in the form

$N_{m}=n\left[1-\exp \left(-\frac{\hbar \omega_{c}}{k T}\right)\right] \exp \left(-\frac{m \hbar \omega_{c}}{k T}\right)$,

where $n=\sum_{m} N_{m}$. Then the total concentration of filled traps with energies $E>E_{i}$ is

$\sum_{m>i} N_{m}=n \exp \left(-\frac{E_{T}}{k T}\right)$. 
During the time of the thermodynamic equilibrium establishment between a trap and the crystal lattice, $\tau_{i T}$, the occupation of high vibrational levels $(m \geqslant i)$ takes place in filled traps that lost an electron, i.e. the electron transits into the conduction band. Thus, within this time interval, the thermal delocalization of the following part of filled traps takes place:

$\frac{\sum_{m>i} N_{m}}{\sum_{m} N_{m}}=\exp \left(-\frac{E_{T}}{k T}\right)$.

So, we obtain the integral probability of the electron delocalization from traps due to the population of vibrational states located above the conduction band bottom:

$\omega_{T}=\frac{1}{\tau_{T}} \exp \left(-\frac{E_{T}}{k T}\right)$.

This formula is identical to the probability of the thermal delocalization of electrons from traps, if the frequency factor is equal to the reciprocal time of the thermodynamic equilibrium establishment between the traps of this type and the crystal lattice.

Thus, the consideration of the vibrational level population in an ensemble of identical filled traps allows the physical origin of the parameter, which is conventionally called the frequency factor, to be determined. Indeed, when considering any thermally activated processes (delocalization of charge carriers from traps, internal and external luminescence fadings, hopping conductivity, diffusion, adsorption, etc.), a large number of centers are always dealt with. The probability of the thermal activation process is an averaged parameter for a statistical ensemble of identical centers, which are in thermodynamic equilibrium with the environment. The reciprocal value of the frequency factor is the relaxation time of centers into the equilibrium state with their environment. Formula (3) obtained for the frequency factor explains its dependence on the trap depth in crystalline phosphor. Really, in deeper traps, an electron, since the moment of its localization, needs more time to transit over vibrational levels onto the lower vibrational levels in the process of thermalization, because those transitions take place sequentially through every next vibrational level. Therefore, the time required for establishing a thermodynamic equilibrium is longer for deep traps. As a result, the frequency factor decreases, as the trap depth

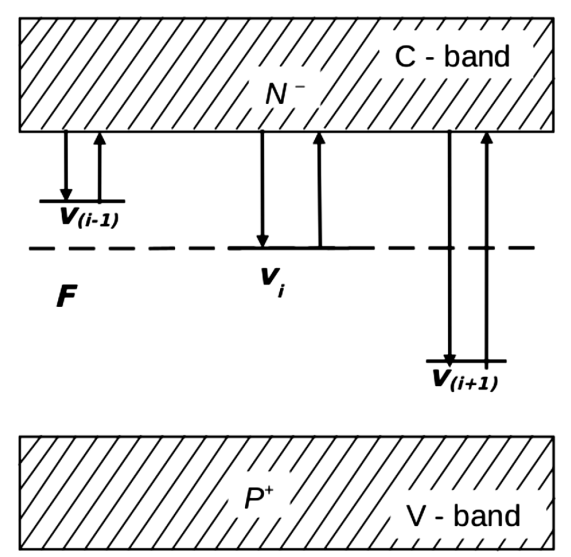

Fig. 1. Schematic diagram of electron transitions into traps

increases. This consideration can be generalized onto all thermal activation processes, since they are based on the same mechanism: transitions over the vibrational states of a large ensemble of identical centers (or molecules) in the course of thermodynamic equilibrium establishment.

\section{Occupation Degrees of Traps Located at Various Depths}

Experimental studies of TSL testify that every crystal contains a significant number of traps. Therefore, it is reasonable to classify the traps of all types into shallow, phosphorescent, and deep ones for every excitation temperature $T_{0}$. For this purpose, three criteria can be used: (i) the average lifetime of a charge carrier in the trap, $\tau_{i}$; (ii) the maximum occupation degree of the trap at its long excitation, i.e. when the quasiequilibrium state is attained, $n_{i} / v_{i}$; and (iii) the trap energy location with respect to the electron Fermi level in the forbidden gap. However, those criteria provide the same result. At the temperature $T_{0}$, traps for which $\tau_{i-1} \ll 1 \mathrm{~s}, n_{(i-1)} / v_{(i-1)} \ll 1$, and which are located above the Fermi level (at least by a few $k T$ ) are classified as shallow ones. For phosphorescent traps (there is only one phosphorescent type), $\tau_{i-1} \approx(1 \div 10) \mathrm{s}, n_{i} / v_{i} \approx 1 / 2$, and they are located near the Fermi level. Traps belonging to this type give the main contribution to the phosphorescence intensity. Finally, the traps located below the Fermi level in the forbidden gap and such that $\tau_{i+1} \gg 10 \mathrm{~s}, 1 / 2<n_{(i-1)} / v_{(i-1)}<1$ are considered as deep ones. Figure 1 illustrates the energy positions of trap levels in the forbidden gap and the 


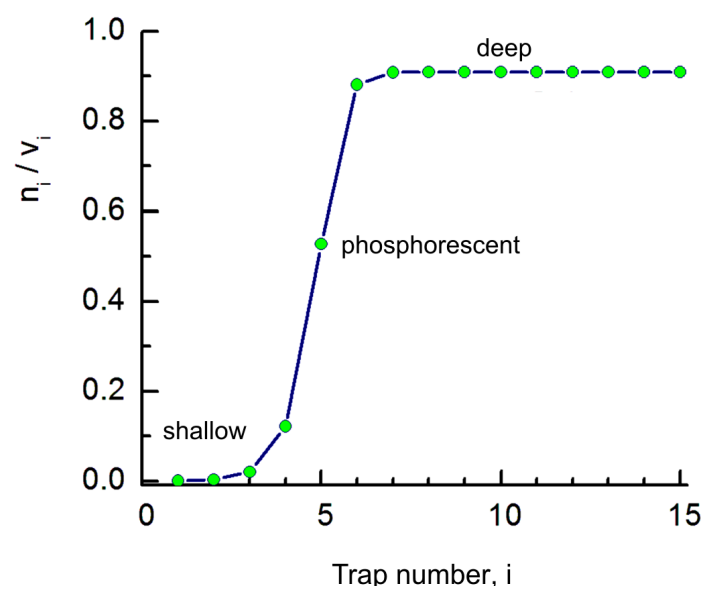

Fig. 2. Occupation degrees of traps in $\mathrm{ZnSe}$ at $T_{0}=85 \mathrm{~K}$. The parameter values are $G=10^{17} \mathrm{~cm}^{-3} \mathrm{~s}^{-1}, \nu_{i}=10^{17} \mathrm{~cm}^{-3}$, and $\nu_{p}=10^{18} \mathrm{~cm}^{-3}$

corresponding electron transitions at the localization and delocalization.

In work [10], in the framework of the described model of crystalline phosphor, the following equation was obtained for the occupation degree of the $i$-th traps:

$\frac{n_{i \infty}}{\nu_{i}}=\frac{1}{2} \sqrt{\left(\frac{G}{\omega_{i} \nu_{i}} \frac{\nu_{i}+\nu_{p}}{\nu_{p}}\right)^{2}+\frac{4 G}{\omega_{i} \nu_{i}}}-\frac{G}{\omega_{i} \nu_{i}}\left(\frac{\nu_{i}+\nu_{p}}{\nu_{p}}\right)$,

where $G$ is the intensity of the electron-hole pair generation per unit volume per unit time, and $\nu_{p}$ is the concentration of recombination centers, at which free holes are localized. Figure 2 demonstrates the occupation degrees of traps in ZnSe at $T_{0}=85 \mathrm{~K}$ calculated by this formula. The corresponding $\omega_{i 0}$-values were taken from Table.

For the indicated relations between the trap and recombination center concentrations, we obtain that the recharge degree of deep traps can reach $91 \%$ at their long excitation, if there is no optical delocalization of electrons from deep traps during the excitation. The corresponding value for the fluorescence centers equals $9 \%$. Thus, the concentration ratio between the shallow and deep traps changes with the excitation temperature $T_{0}$, which significantly affects the luminescence and conductivity kinetics.

\section{Cross-Sections $\sigma_{i}$ of Electron Localization at Traps}

Let us assume that all traps can exchange electrons with the conduction band only, although sometimes - for example, in alkaline halide crystals $[18,19])$ - the tunnel transitions from a trap into the recombination centers were observed. All localization and delocalization events are independent of one another, which allows the occupation degree of every trap and its parameters to be determined by considering only one kinetic equation from the general system of kinetic equations.

\subsection{Cross-section of the free-electron localization at shallow traps}

In order to determine the cross-sections of the freeelectron localization at shallow traps, let us consider the kinetic equation for one shallow trap. In the stationary state, the Fermi level lies below the local level of a shallow trap (Fig. 1). For the concentration $n_{(i-1)}$ of localized electrons at the traps of the $(i-1)$-th type with the concentration $v_{(i-1)}$ at the temperature $T_{0}$, we have the kinetic equation

$$
\begin{aligned}
& \frac{d n_{(i-1)}}{d t}=N^{-} u^{-} \sigma_{(i-1)}^{-}\left(\nu_{(i-1)}-n_{(i-1)}\right)- \\
& -\omega_{(i-1)} n_{(i-1)}=0
\end{aligned}
$$

where $N$ is the concentration of free electrons in the conduction band, $u^{-}=\sqrt{\frac{2 k T}{3 m_{e}^{*}}}$ is their thermal velocity, $\sigma_{(i-1)}^{-}$the localization cross-section, and $\omega_{(i-1)}$ the probability of the thermal delocalization. The occupation degree of all shallow traps is very low, and the inequality $n_{(i-1)} \ll \nu_{(i-1)}$ is valid. This circumstance allows Eq. (9) to be simplified:

$\frac{N^{-}}{n_{(i-1)}}=\frac{\omega_{0(i-1)} \exp \left(-E_{(i-1)} / k T\right)}{u^{-} \sigma_{(i-1)}^{-}}$

so that we obtain a direct proportionality between the concentrations of free electrons and electrons localized at shallow traps. But, in the stationary state case, this concentration ratio should also satisfy the Boltzmann distribution, because the Fermi level is located below the local trap level, and $E_{i-1}$ is the distance between the conduction band and the trap level,

$\frac{N^{-}}{n_{(i-1)}}=\frac{N_{\mathrm{C}}}{\nu_{(i-1)}} \exp \left(-E_{(i-1)} / k T\right)$,

where

$N_{\mathrm{C}}=2 \frac{\left(2 \pi m_{e}^{*} k T\right)^{3 / 2}}{h^{3}}$

ISSN 2071-0194. Ukr. J. Phys. 2019. Vol. 64, No. 4 
is the effective density of electron states in the conduction band, $m_{e}^{*}$ is the effective electron mass, and $h$ is Planck's constant. By comparing Eqs. (9) and (10), we obtain the following formula for the localization cross-section:

$\sigma_{(i-1)}^{-}=\frac{\omega_{0(i-1)}}{u^{-} N_{\mathrm{C}}}$.

This expression for the cross-section of free-electron localization at shallow traps was obtained in work [3], but from a different reasoning.

\subsection{Cross-section of free-electron localization at phosphorescent traps}

The phosphorescent trap provides the major part of the phosphorescence and the conduction current relaxation at the excitation temperature $T_{0}$ (the trap of the $i$-th type). This means that the Fermi level is located near the level of this trap in the stationary state. To simplify calculations, we assume that the Fermi level exactly coincides with the trap level. Then the kinetic equation for localized electrons reads

$\frac{d n_{(i)}}{d t}=N^{-} u^{-} \sigma_{(i)}^{-}\left(\nu_{(i)}-n_{(i)}\right)-\omega_{(i)} n_{(i)}=0$.

In the stationary state, this trap is half-occupied, and the condition $E_{i} \gg k T$ is satisfied, i.e.,

$$
\begin{aligned}
& n_{i}=\frac{1}{2} \nu_{i}, \\
& N^{-}=N_{\mathrm{C}} \frac{1}{\exp \left(E_{i} / k T\right)+1}=N_{\mathrm{C}} \exp \left(\frac{-E_{i}}{k T}\right) .
\end{aligned}
$$

As a result, we obtain

$$
N_{\mathrm{C}} \exp \left(\frac{-E_{i}}{k T}\right) u^{-} \sigma_{(i)}^{-} \frac{\nu_{(i)}}{2}=w_{0 i} \exp \left(\frac{-E_{i}}{k T}\right) .
$$

From whence, we have

$\sigma_{(i)}^{-}=\frac{w_{0 i}}{u^{-} N_{\mathrm{C}}}$.

This is the equation for the cross-section of the freeelectron localization at a phosphorescent trap. It is identical to Eq. (11).

\subsection{Cross-section of free-electron localization at deep traps}

In order to determine the cross-section of the freeelectron localization at a deep trap, let us consider a model of crystalline phosphor with one deep donor level (Fig. 1). From the physical viewpoint, this donor does not differ from a deep trap in the excited crystalline phosphor in the stationary state. This trap will be denoted by the subscript $(i+1)$. In the model concerned, the Fermi level for electrons is located between the local level of the trap and the conduction band bottom. The corresponding kinetic equation for the stationary state at the temperature $T_{0}$ looks like

$$
\begin{aligned}
& \frac{d n_{(i+1)}}{d t}=N^{-} u^{-} \sigma_{(i+1)}^{-}\left(\nu_{(i+1)}-n_{(i+1)}\right)- \\
& -\omega_{(i+1)} n_{(i+1)}=0 .
\end{aligned}
$$

Taking into account that $v_{(i+1)}-n_{(i+1)}=N^{-} \ll$ $\ll v_{(i+1)}$, this equation can be somewhat simplified,

$\left(N^{-}\right)^{2} u^{-} \sigma_{(i+1)}^{-}=w_{0(i+1)} \nu_{(i+1)} \exp \left(-\frac{E_{(i+1)}}{k T}\right)$.

The concentration of free electrons obeys the Fermi statistics, and this parameter can be written in the form

$N^{-}=\sqrt{N_{\mathrm{C}} \nu_{(i+1)}} \exp \left(-\frac{E_{(i+1)}}{k T}\right)$,

i.e. as the intrinsic conductivity of a semiconductor [29], in which the deep level plays the role of a valence band, because the thermal ionization of local levels determines the free-electron concentration. As a result, we obtain

$$
\begin{aligned}
& N_{\mathrm{C}} \nu_{(i+1)} \exp \left(-\frac{2 E_{(i+1)}}{k T}\right) u^{-} \sigma_{(i+1)}^{-}= \\
& =\omega_{0(i+1)} \nu_{(i+1)} \exp \left(-\frac{E_{(i+1)}}{k T}\right) .
\end{aligned}
$$

From whence, we have a formula for the cross-section of the free-electron localization at deep traps:

$\sigma_{(i+1)}^{i}=\frac{\omega_{0(i+1)}}{u^{-} N_{\mathrm{C}}}$

Thus, the formulas obtained for the cross-sections of the free-electron localization at shallow [Eq. (11)], phosphorescent [Eq. (14)], and deep [Eq. (16)] traps look almost identically. Therefore, we may assert that a universal formula should be valid for traps of all kinds in semiconductors and insulators. Since $u$ and 


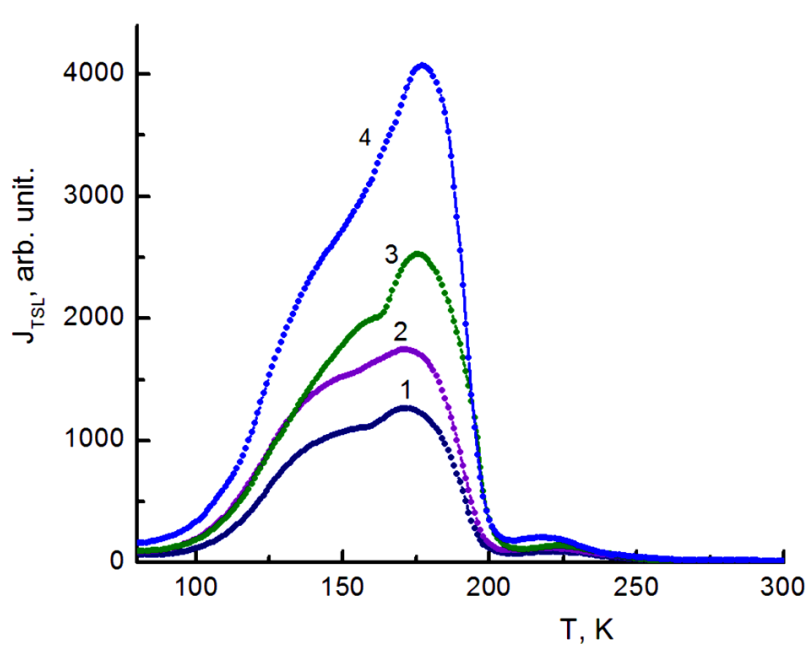

Fig. 3. TSL curves for the ZnSe crystal after X-ray excitation $\left(I_{X}=0.63 \mathrm{~mW} / \mathrm{cm}^{2}\right)$ for $1(1), 5(2), 10(3)$, and $25 \mathrm{~min}(4)$

$N_{\mathrm{C}}$ are the crystal lattice parameters, and the frequency factor is determined by Eq. (3), the formula for the cross-section of the free-electron localization at a trap of the $j$-th type at the temperature $T_{0}$ can be written as follows:

$\sigma_{j}^{-}=\sqrt{\frac{3}{\pi}} \frac{\omega_{0 j} h^{3}}{8 \pi m_{e}^{*}(k T)^{2}}=\sqrt{\frac{3}{\pi}} \frac{A \beta h^{3} \exp (A)}{8 \pi m_{e}^{*} k^{2} T_{0}^{2} T_{j}}=$

$=\sqrt{\frac{3}{\pi}} \frac{A^{2} \beta h^{3} \exp (A)}{8 \pi m_{e}^{*} k T_{0}^{2} E_{j}}$.

A reduction of the localization cross-section for deep traps was experimentally found in YAG crystals long ago [30]. This behavior is also confirmed by the TSL curves obtained for ZnSe after various irradiation doses: less deep traps accumulate light sums quicker than deeper ones do. The curve shape of TSL in ZnSe appreciably varies as the dose of Xray radiation increases (Fig. 3). This fact confirms that the localization cross-section for deep traps decreases proportionally to the trap depth according to Eq. (17). The free-electron localization cross-sections also decrease with the growth of the excitation temperature, $\sigma_{j} \sim T_{0}^{-2}$. This means that the crosssections of the electron localization at traps become $(295 / 8)^{2} \approx 1360$ times smaller at room temperature, if compared with the values given in Table. Furthermore, if we take into account that almost all traps become shallow at room temperature, the application of ZnSe crystals as semiconductor detectors of ionizing radiation seems to be attractive. The calculated localization cross-sections for traps in ZnSe are quoted in Table. For the localization of free holes at traps, the whole analysis will be the same to within the substitution of the parameter $N_{\mathrm{C}}$ by $N_{V}$ in formulas (11), (14), and (16).

\section{Conclusions}

If the energy spectrum of traps and the temperatures of the TSL peak maxima are known, the corresponding frequency factors and the localization crosssections for free charge carriers at those traps can be calculated. The consideration of the kinetic equations for traps with various depths brought us to the equation describing the cross-sections of the electron localization at traps in terms of their frequency factor, heat velocity, and the effective density of electron states in the conduction band. It is found that the dependence of the localization cross-section on the excitation temperature is proportional to $T_{0}^{-2}$, which is confirmed experimentally. It is also found that the physical sense of the frequency factor consists in that this quantity is a reciprocal value to the average time of establishing the thermodynamic equilibrium between a local center and the crystal lattice. The information about the main parameters of traps makes it possible to analyze a lot of experimental kinetic dependences for luminescence and conductivity, such as the enhancement of luminescence and conductivity, the dose dependences of phosphorescence and conduction current relaxation, the dose dependences of the TSL peak intensity and the TSC current, etc.

1. M.V. Fok. Introduction to Luminescence Kinetics of Crystal Phosphors (Nauka, 1964) (in Russian).

2. V.V. Antonov-Romanovskii. Photoluminescence Kinetics of Crystal Phosphors (Nauka, 1966) (in Russian).

3. R.H. Bube. Photoconductivity of Solids (Wiley, 1960).

4. V.E. Lashkarev, A.V. Lyubchenko, M.K. Sheinkman. Nonequilibrium Processes in Photoconductors (Naukova Dumka, 1981) (in Russian).

5. I.Ya. Gorodetskii, K.K. Dubenskii, V.E. Lashkarev et al. Determination of parameters of recombination centers in ZnSe monocrystals. Fiz. Tekh. Poluprovodn. 1, 1666 (1967) (in Russian).

6. A.V. Lyubchenko, M.K. Sheinkman. Determining sticking centers parameters in semiconductors on the temperature dependence of the photocurrent. Ukr. Fiz. Zh. 18, 134 (1973) (in Russian).

7. D.M. Freik, A.M. Voznyak, T.O. Paraschuk, V.M. Chobanyuk, I.V. Gorychok. Localized states of electrons in 
semiconductors. II. Experimental methods of research (A review). Fiz. Khim. Tverd. Tila 12, 445 (2011) (in Ukrainian).

8. A. Chruscinska, H.L. Oczkowski. K.R. Przegietka. The parameters of traps in K-feldpars and the TL bleaching efficiency. Geochronometria 20, 15 (2001).

9. P.N. Brunkov, A.A. Gutkin, V.V. Chaldyshev, N.N. Bert, S.G. Konnikov, V.V. Preobrazhenskii, M.A. Putyato, B.R. Semyagin. Electron traps in thin layers of the low temperature grown gallium arsenide with $\mathrm{As}-\mathrm{Sb}$ nanoclusters. Fiz. Tekh. Poluprovodn. 39, 1049 (2005) (in Russian).

10. V.Ya. Degoda, A.F. Gumenyuk, Yu.A. Marazuev. Kinetics of Recombination Luminescence and Conductivity of Crystal Phosphors (Kyiv Nat. Univ. Publ. House, 2016) (in Ukrainian).

11. I.S. Gorban, A.F. Gumenyuk, V.A. Omel'yanenko. Thermoluminescence and polaron states in barium-sodium niobate crystals. Ukr. Fiz. Zh. 33, 530 (1988) (in Russian).

12. A.F. Gumenyuk, S.Yu. Kutovyi, O.B. Okhrimenko. Oscillator regularities in the trap energy spectra of $\mathrm{CdWO}_{4}$ crystals. Ukr. Fiz. Zh. 42, 870 (1997) (in Ukrainian).

13. I.S. Gorban, A.F. Gumenyuk, S.Yu. Kutovyi. Oscillatory dependences in trap energies in $\mathrm{ZnWO}_{4}$ crystals. Ukr. Fiz. Zh. 40, 73 (1995) (in Ukrainian).

14. A.F. Gumenyuk, S.Yu. Kytovyi, M.O. Grebenovich. Oscillatory regularity in the trap activation energies in a- $\mathrm{Al}_{2} \mathrm{O}_{3}$ crystals. Funct. Mater. 9, 314 (2002).

15. G.P. Blinnikov, V.N. Golonzhka, A.F. Gumenyuk. Thermal properties of single crystals $\mathrm{CsCdCl}_{3}$. Opt. Spektrosk. 69, 1054 (1990) (in Russian).

16. I.S. Gorban, A.F. Gumenyuk, V.Ya. Degoda, S.Yu. Kutovyi. Regularities of the energy spectrums of charge carrier delocalization from traps in YAG. Opt. Spektrosk. 75, 47 (1993) (in Russian).

17. A.F. Gumenjuk, S.Yu. Kutovyi. Oscillator rule of the trap activation energies in $\mathrm{NaCl}$ crystals. Centr. Eur. J. Phys. 1, 307 (2003).

18. A.F. Gumenjuk, S.Yu. Kutovyi. Thermoluminescence studies of undoped LiF crystals. II. The oscillator-like regularity in trap activation energies. Ukr. Fiz. Zh. 50, 1125 (2005) (in Ukrainian).

19. A. Gumenyuk, S. Kutovyi, V. Pachshenko, O Stanovyi. Oscillator rule in the energy spectrum of traps in $\mathrm{KCl}$ and NaI crystals. Ukr. Fiz. Zh. 54, 999 (2009) (in Ukrainian).

20. D. Curie. Luminescence in Crystals (Wiley, 1963).

21. I. Tale, J. Rosa. Fractional glow technique spectroscopy of traps in heavily doped AIN:O. Phys. Status Solidi A 86, 319 (1984).
22. H.J. Beaven. A model for thermoluminescence and related phenomena in $\mathrm{PbSO}_{4}$ :Sm. J. Phys. D 21, 181 (1988).

23. I.N. Ogorodnikov, A.V. Porotnikov, A.V. Kruzhalov, V.Yu. Yakovlev. Recombination kinetics in nonlinear defective $\mathrm{LiB}_{3} \mathrm{O}_{5}$ crystals. Fiz. Tverd. Tela 40, 1817 (1998) (in Russian).

24. V. Degoda, A. Gumenjuk, N. Pavlova, A. Sofiienko, S. Sulima. Oscillatory regularity of charge carrier trap energy spectra in ZnSe single crystals. Acta Phys. Polon. 129, 304 (2016).

25. A.M. Gurvich. Introduction to Physical Chemistry of Crystal Phosphors (Vysshaya Shkola, 1982) (in Russian).

26. A.M. Gurvich. X-Ray Luminophores and Screens (Energoatomizdat, 1976) (in Russian).

27. N.A. Anisimov, S.A. Baryshev, A.F. Gomenyuk, I.S. Gorban, V.Ya. Degoda. Energy spectrum of the traps in $\mathrm{Y}_{3} \mathrm{Al}_{5} \mathrm{O}_{12}$. Zh. Prikl. Spektrosk. 25, 1320 (1976) (in Russian).

28. K.K. Shvarts, Z.A. Grant, T.K. Mezhs, M.M. Grube. Thermoluminescent Dosimetry (Zinatne, 1968) (in Russian).

29. K.V. Shalimova, Physics of Semiconductors (Energoatomizdat, 1985) (in Russian).

30. I.S. Gorban, A.F. Gumenyuk, V.Ya. Degoda, T.A. Kuchakova. Thermoluminescence with non-uniform accumulation of the light sum in YAG: $\mathrm{Nd}_{3}+$ crystals. Ukr. Fiz. Zh. 31, 370 (1986) (in Russian).

Received 20.12.17.

Translated from Ukrainian by O.I. Voitenko

В.Я. Дегода, М. Алізадех

\section{ПАРАМЕТРИ ПАСТОК ДЛЯ НОСІЇВ ЗАРЯДУ В ZnSe}

Р е $з$ ю м е

На прикладі кристалів селеніду цинку (ZnSe) запропонована система визначення основних параметрів пасток. Спочатку за допомогою фотоелектричних досліджень, або досліджень термоемісійного струму, або термо- і фототермоерс, визначають характер провідності (електронний чи дірковий) в кристалофосфорі при збудженні. Далі визначаються енергії термічної делокалізації електронів, наприклад, методом послідовного фракційного нагрівання термостимульованої люмінесценції. При цьому також визначаються частотні фактори для відповідних пасток. Знаючи ефективну масу електрона легко вираховується ефективна густина станів електронів у зоні провідності. I в результаті з простого рівняння можна визначити перерізи локалізації вільних електронів на усі пастки та їх температурні залежності. 